\title{
Audioteca Virtual de Letras: tecnologia para inclusão
}

\section{Marcus Vinícius Liessem FONTANA ${ }^{1}$ EIton L. VERGARA NUNES ${ }^{* * *}$}

\begin{abstract}
Resumo: O projeto Audioteca Virtual de Letras, da Universidade Federal de Pelotas, utiliza-se das facilidades criadas pelas novas tecnologias voltadas para educação a fim de disponibilizar, via internet, arquivos de áudio com obras ou trechos de obras literárias para que pessoas com deficiência visual possam ter acesso fácil e gratuito a este material. Os arquivos são gravados em um pequeno estúdio caseiro, montado e mantido pelo professor responsável. As gravações são realizadas com a colaboração de alunos da Faculdade de Letras que trabalham de forma voluntária, lendo textos em português e espanhol. Os textos são gravados e editados por meio de um microcomputador e disponibilizados em um espaço virtual na internet. Além de pessoas cegas, o projeto beneficia também a professores, estudantes e fãs da literatura em geral. Em breve, o projeto será expandido, por meio de uma nova Audioteca Virtual, que contemplará o Curso de Licenciatura de Matemática a Distância, disponibilizando textos didáticos e artigos da área para estudantes com deficiência visual.
\end{abstract}

Palavras-chaves: audioteca; educação; tecnologias; inclusão; deficiência visual.

\section{Virtual Audio Library of Letters: technology for inclusion}

Abstract: The Virtual Audio Library of Letters is a project developed by the Federal University of Pelotas. This project uses technological tools to provide audio files containing whole (or part of) literary works in the Internet. Its goal is to offer free (and easy) access to these works for blind people. The files are recorded in a homemade small studio installed and maintained by the professor responsible for the project. Undergraduate students from the Letters Course have worked voluntarily by reading texts in Portuguese and Spanish that are recorded and edited in a microcomputer. The produced files are put on a virtual site and are available on Internet. Besides the benefits just presented the project may also help teachers, students and literature fans. This project intends to be expanded soon by including mathematics and mathematics teaching texts in the site in order to attend the Distance Mathematics Course of the Federal University of Pelotas.

Keywords: audio library; education; technologies; inclusion; blind.

\section{INTRODUÇÃO}

A Audioteca Virtual de Letras da Universidade Federal de Pelotas (UFPel) surgiu como projeto complementar à Biblioteca Virtual de Letras (BVL), no ano de 2004, a partir das pesquisas levadas a cabo por seu coordenador, Professor Mestre Elton Luiz Vergara Nunes, e concretizou-se graças à colaboração de alunos das áreas de português, espanhol e francês do Curso de Letras desta mesma universidade.

O objetivo fundamental da Audioteca é o de disponibilizar, através da internet, arquivos de áudio com leituras de trechos ou mesmo de obras completas da literatura de

\footnotetext{
${ }^{1}$ Graduando do Curso de Letras - Língua Espanhola da Universidade Federal de Pelotas, Colaborador do Projeto Audioteca Virtual de Letras, membro da equipe do Laboratório de Ensino de Matemática a Distância (LEMAD) da Universidade Federal de Pelotas, marcusvfontana@yahoo.com.br, http://www.ufpel.edu.br/clmd/.

** Mestre em Educação, Coordenador do Projeto Audioteca Virtual de Letras e do Laboratório de Ensino de Matemática a Distância (LEMAD) da Universidade Federal de Pelotas, professor da área de espanhol do Departamento de Letras Estrangeiras da Faculdade de Letras da UFPel, vergaranunes@gmail.com, http://www.ufpel.edu.br/clmd/. 
língua portuguesa, bem como da literatura universal, tanto clássicas como contemporâneas, para que pessoas com deficiência visual possam ter acesso a tais obras.

Esta disposição tem por força-motriz o inegável avanço dos estudos relacionados à inclusão e aos direitos das pessoas com deficiências, e visa a preencher uma lacuna no que tange ao acesso dos deficientes visuais às obras literárias. Tudo isso, em uníssono com o texto da Declaração dos Direitos do Deficiente, da Organização das Nações Unidas, datado do já longínquo ano de 1981, segundo o qual:

- O deficiente tem os mesmos direitos civis e políticos dos demais seres humanos;

- O deficiente tem direito às medidas destinadas a permitir-lhe alcançar a máxima autonomia possível;

- O deficiente tem direito à [...] educação, à formação e readaptação profissionais;

- O deficiente tem direito a que sejam levadas em conta suas necessidades particulares em todas as etapas do planejamento econômico e social. (UNESCO, 1981)

A verdade, entretanto, é que no Brasil estes direitos tão básicos das pessoas com deficiência estão muito longe de se tornarem uma realidade, principalmente se vivem afastadas dos grandes centros urbanos. Veja-se o que diz Góes a este respeito:

Os deficientes visuais fora das capitais do Brasil não têm acesso a nada: - Virtualmente todas as ínfimas facilidades para deficientes visuais estão localizadas nas capitais. Um cego que nasça no interior é um aleijado da cultura. (Góes, 2005)

Ao considerar esta triste realidade e com vistas a dar um pequeno passo no sentido de mudá-la, decidiu-se dar início às pesquisas para viabilizar a criação da Audioteca. Neste caminho, entretanto, avaliamos outros meios de acesso dos cegos à literatura, com a intenção de entender se tais meios satisfaziam em cem por cento as necessidades das pessoas com deficiência visual e, assim, medir a relevância ou não do projeto.

\section{MEIOS INVESTIGADOS}

Evidentemente, existem algumas maneiras de facilitar o contato de deficientes visuais com a literatura, que hoje já são consagradas, uma delas é a escrita braile.

Entre as questões levantadas a respeito dos livros produzidos neste formato, encontramos alguns problemas. Em primeiro lugar, a leitura em braile é algo bastante especializado, necessitando de escolas especiais e pessoal preparado para seu ensino. $\mathrm{O}$ número de cidades brasileiras que possuem escolas capazes de ensinar este alfabeto é relativamente reduzido. Além disso, o custo deste tipo de livros é bastante alto contrastando com o pequeno número de publicações e as reduzidas tiragens. Atualmente, apenas duas instituições produzem livros em braile no Brasil: a Fundação Dorina Nowill (São Paulo) e o Instituto Benjamin Constant (Rio de Janeiro). Boa parte desta produção é de livros didáticos. O governo federal adquire a maior parte do que é impresso e distribui este material segundo critérios próprios. Como consequiência, grande parte dos deficientes visuais tem dificuldade de acesso a este meio, principalmente quando nos remetemos a cidades pequenas, onde, em geral, inexistem projetos voltados ao bem-estar deste grupo e, quando existem, há pouco interesse e suporte, tanto do governo como da iniciativa privada.

Outro meio estudado foi o dos programas de computador como o Virtual Vision ou o DOSVOX, apenas para citar dois exemplos. 
Estes programas visam ao auxílio dos deficientes visuais, convertendo, por meio de sintetizadores de voz, o texto que aparece na tela do computador em texto falado. Esta tecnologia apresenta algumas vantagens com relação ao livro em braile em termos de acessibilidade. Isso acontece porque qualquer pessoa em qualquer lugar do país ou do mundo, munida de um terminal de computador e um acesso à internet, tem condições de copiar, de forma gratuita, das diversas bibliotecas virtuais especializadas existentes na rede mundial, inúmeras obras digitalizadas. Estas mesmas obras são "lidas" por programas como os mencionados, que fazem às vezes de um leitor presencial.

Pode-se objetar que não são todas as pessoas cegas ou com deficiência visual menos severa que podem contar com um computador e uma conexão à internet, mas esta realidade está mudando. Veja-se, mais uma vez, o que diz Góes a este respeito:

Dados do projeto Intervox dão o número de usuários [de internet] cegos o Brasil, em Outubro de 1998 como mais de 500. As maiores aplicações da Internet, que são hoje o correio eletrônico e o acesso à World Wide Web (homepages), encontram nos cegos usuários com alto interesse. Esses usuários fazem acesso especialmente ao correio eletrônico, jornal diário, diversos livros, cotação de algumas lojas de eletrodomésticos, artigos variados retirados da revista 'Veja', 'Isto É' e outras, levantamentos bibliográficos e busca de produtos relativos à deficiência visual. Para a pessoa cega, a comunicação pela Internet é especialmente importante por duas razões: a eliminação da necessidade da locomoção, que é normalmente um entrave para o cego, e o fato de que do outro lado da Internet, ninguém precisa realmente saber se o parceiro é ou não cego. Assim, pelo menos numa comunicação inicial, a pessoa cega é vista como uma pessoa não deficiente pelo parceiro. (Góes, 2005)

Perceba-se que os dados são de 1998, ainda nos começos da rede mundial no Brasil, e que, desde então, a informática e especialmente a internet têm dado passos gigantescos em termos de avanços e melhorias em geral. O próprio projeto DOSVOX, por exemplo, tem ganhado terreno rapidamente, conforme Silveira:

O Projeto "DOSVOX", iniciado em 1993 pelo Professor José Antônio dos Santos Borges, auxiliado por equipe onde se destacam o Engenheiro Fujio Takano, projetista do sintetizador de voz, o analista Orlando José Rodrigues Alves, Luis Cândido e o aluno deficiente visual, Marcelo Luis Pimentel Pinheiro, vem sendo aperfeiçoado, incluindo versão para windows (winvox), pelos próprios programadores portadores de deficiências visuais, possibilitando aos usuários operar computadores através de sons, propiciando uso de diversos programas sonorizados, dentre eles, agenda de compromissos, calculadoras, editores de textos e de cartas, jogos, e relógios. Este sistema permite, portanto, a execução de diversas tarefas, como editar textos, gerar relatórios que podem ser impressos em equipamento comum ou impressora Braille, ler (ouvir) textos que tenham sido transcritos para o winchester ou para disquetes.

$[\ldots]$

O sucesso desse Projeto, cujas tecnologias propiciam utilização por centenas de cegos do Brasil, é atribuído principalmente ao 
baixo custo do sistema computacional, à simplicidade de tecnologia de produção, considerado viável às indústrias nacionais, possibilidade de fala e de leitura em língua portuguesa, interface amigável de comunicação homemmáquina, obediência às restrições/limitações e características da maioria das pessoas cegas leigas. (Silveira, 1999)

O grande problema deste sistema, entretanto, segundo relatos dos próprios deficientes visuais, é a formalidade e mecanicidade da voz sintetizada pelo computador. O prazer da audição é consideravelmente minorado pela máquina e torna o texto, muitas vezes, incompreensível. Percebe-se, então, que os programas informáticos roubam um pouco da "magia" da leitura, obrigando o leitor a um ritmo monótono, sem emoção e sem inflexão.

Em pesquisa realizada na Universidade Luterana de Palmas (TO), no ano de 2004, por exemplo, foi questionado a alguns usuários com deficiência visual sobre a qualidade da voz produzida pelo sintetizador, com o intuito de saber se o sistema garantiria um bom entendimento da informação contida no texto lido. As opiniões colhidas tiveram mais ou menos o mesmo teor das que abaixo são reproduzidas:

- Muito ruim, entendeu algumas palavras, mas não conseguiu entender o texto.

- Baixa qualidade, porém conseguiu abstrair algumas informações contidas no texto. (Gomes, 2004)

Em síntese, portanto, pode-se perceber que tanto as obras em braile quanto os programas com sintetizador de voz apresentam alguns problemas e entraves graves ao acesso dos cegos à literatura.

Ao refletir sobre esta problemática, surgiu o imperativo de elaborar um sistema que, ao mesmo tempo, solucionasse as questões do alto custo, da demanda por novas obras e que trouxesse para a leitura a tão indispensável emoção humana, que dá o tom fascinante e hipnótico da literatura.

\section{PROJETOS INSPIRADORES}

Ao realizar-se exaustiva pesquisa em obras especializadas, bem como em sites relacionados ao assunto em busca de uma solução, surgiu o tema dos chamados livros falados, conceito amplamente divulgado no Brasil pelo Instituto Benjamin Constant (IBC), do Rio de Janeiro, órgão do Ministério da Educação que há 40 anos apóia um projeto neste sentido, elaborado pelo professor Benno Arno Marquadt.

O projeto do Instituto, chamado Grupo da Boa Leitura, iniciou-se com a leitura de obras de lábios a ouvidos e estendeu-se para a gravação de cassetes, realizada por voluntários de todo o país. Os cassetes são catalogados, arquivados e disponibilizados na audioteca do Instituto para empréstimo, da mesma maneira que em uma biblioteca comum. Atualmente, este projeto encontra alguns similares em outras localidades do Brasil, podendo-se destacar projetos como a Fundação Dorina Nowill para Cegos e a Audioteca Sal e Luz.

Ao tomarmos conhecimento desta forma de trabalho, a associação com o projeto já existente da Biblioteca Virtual de Letras foi imediata. Ora, se o IBC mantém fisicamente um acervo de obras lidas, por que não poderíamos manter um acervo virtual de arquivos de áudio, da mesma maneira que já vinha sendo feito com as obras em formato texto na Biblioteca Virtual de Letras?

Pois como resposta a este questionamento surgiu o projeto batizado como Audioteca Virtual de Letras. 


\section{A QUESTÃO DOS DIREITOS AUTORAIS}

A primeira questão que causou preocupação no projeto foi com relação aos direitos autorais.

Sabe-se que no Brasil os direitos autorais prescrevem após 70 anos da morte do autor, porém é evidente que as pessoas com deficiência visual necessitam estar atualizadas e têm todo o direito de conhecer também as obras importantes da atualidade, afinal de contas, seus direitos, conforme se viu no trecho da Declaração dos Direitos do Deficiente anteriormente analisado, são os mesmos que os de qualquer outra pessoa.

Para evitar incorrer em ações ilegais, buscou-se o texto da lei federal número 9610, de 19 de fevereiro de 1998, que versa sobre direitos autorais em nosso país, a fim de buscar uma solução para o dilema e nos deparamos com o artigo 46, que diz que:

Não constitui ofensa aos direitos autorais: I - a reprodução: a) na imprensa diária ou periódica, de notícia ou de artigo informativo, publicado em diários ou periódicos, com a menção do nome do autor, se assinados, e da publicação de onde foram transcritos; b) em diários ou periódicos, de discursos pronunciados em reuniões públicas de qualquer natureza; c) de retratos, ou de outra forma de representação da imagem, feitos sob encomenda, quando realizada pelo proprietário do objeto encomendado, não havendo a oposição da pessoa neles representada ou de seus herdeiros; d) de obras literárias, artísticas ou científicas, para uso exclusivo de deficientes visuais, sempre que a reprodução, sem fins comerciais, seja feita mediante o sistema Braille ou outro procedimento em qualquer suporte para esses destinatários.

Com isso, os direitos dos cegos foram resguardados e encontrou-se o respaldo necessário para dar andamento ao projeto. Restava, então, organizar equipamentos, estabelecer um método para as gravações e pensar em uma equipe de pessoas que se dispusessem a fazer as leituras.

\section{ESPAÇO, EQUIPAMENTOS E MÉTODO DE GRAVAÇÃO}

O primeiro passo para a criação da Audioteca foi a aquisição de equipamentos e escolha de softwares para a gravação dos textos.

$\mathrm{Na}$ sua forma atual, o projeto conta com um pequeno estúdio caseiro de gravação, totalmente idealizado, construído e custeado pelo professor coordenador do projeto e que funciona em sua própria casa. Há uma pequena sala de gravação de aproximadamente $1 \mathrm{~m}^{2}$, construída em madeira e revestida internamente com várias camadas de isopor, material que auxilia consideravelmente o tratamento acústico da sala, permitindo uma gravação o mais livre possível de ruídos externos. Na sala de gravação, conta-se com microfone e fone de ouvido para retorno conectado diretamente ao computador do projeto.

Externamente, há um computador adquirido especialmente para o projeto, com placa de som off-board, conectado a um micro system e fones de ouvido. Nesse computador trabalha o editor de som, função desempenhada pelo professor coordenador, que acompanha a qualidade da gravação e orienta a leitura, para evitar que esta se desvie do texto escrito, uma vez que podem ocorrer trocas de letras ou mesmo de palavras em uma leitura. Cabe ao professor a orientação dos ledores segundo o tipo de texto lido. O acompanhamento da leitura é feito através de fone de ouvido acoplado ao computador, a fim de evitar interferências. A orientação é feita tanto do ponto de vista técnico (volume, ruídos etc), como de impostação de voz (dicção, pronúncia, ritmo etc).

O software de edição de áudio usado é o Audacity ${ }^{i}$, em sua versão 1.2.3, que pode ser conseguido de forma totalmente gratuita na internet. Tem a vantagem de ser V.3 $\mathrm{N}^{\mathrm{o}} 2$, Novembro 2005 
leve e rápido, bastante simples em seu manuseio, o que permite um trabalho de edição ágil e eficiente. Com este software podem ser eliminadas pequenas imperfeições que possam ocorrer durante a gravação, o que torna o texto lido mais agradável à percepção do ouvinte. Antes da leitura do texto, o ledor se identifica dizendo seu nome e data da leitura, bem como o nome do Projeto e da Instituição. Esta introdução serve como referência para citação do texto lido.

Terminados os trabalhos de gravação e de edição, o arquivo com a leitura é disponibilizado no site da Audioteca Virtual de Letrasii, cujo acesso é livre e gratuito através da internet, sem necessidade de cadastros ou chaves de acesso. Os arquivos são salvos inicialmente no formato mp3 e imediatamente convertidos para o formato Real Media antes de serem disponibilizados.

O site da Audioteca é um espaço que faz parte da área no servidor da Biblioteca Virtual de Letras, garantido pelo serviço de Internet da UFPel, sem preocupação com tamanho do espaço ou dos arquivos enviados. Para tanto, criou-se um link na página da BVL. Através deste link, abre-se a página da Audioteca com códigos html em modo texto, adaptada aos padrões técnicos estabelecidos para facilitar o uso de deficientes visuais, sem figuras, com alto contraste e letras com corpo grande. Trata-se de uma única página com todas as obras disponíveis, a fim de evitar que o deficiente visual precisa de muitos cliques parta encontrar o arquivo desejado. Nesta página, aparecem listados todos os arquivos disponíveis que, com um simples clique de mouse, podem ser copiados para o computador do usuário. Todos os arquivos estão compactados com extensão .zip e são salvos com formato Real Media, devido ao seu tamanho e por ser o mais usado entre os cegos. O player para a extensão .rm pode ser copiado gratuitamente no site ${ }^{\mathrm{iii}}$ da Real.

\section{OS LEDORES}

Um capítulo que merece destaque na história da Audioteca refere-se aos ledores. Ledor é o termo utilizado e reconhecido universalmente para referir-se às pessoas que realizam leituras para cegos e para pessoas com diferentes níveis de deficiência visual.

Em casos como os do Instituto Benjamin Constant e instituições similares, são voluntários que, de boa vontade, disponibilizam parte de seu tempo para ler e gravar em fitas suas leituras, enviando-as à entidade para disponibilização. Apesar da boa vontade destes voluntários, uma reclamação é recorrente entre os deficientes visuais que se utilizam de seus serviços: muitos não têm a preparação adequada, e sua leitura acaba tornando-se cansativa, pois não respeitam pontuação e não dão a entonação adequada, entre outros problemas.

Para evitar isto, optou-se por fazer uma seleção entre alunos da Faculdade de Letras da UFPel, a fim de escolher os mais aptos para o trabalho. Inicialmente, foram escolhidas duas alunas da Licenciatura de Língua Portuguesa, para leituras em português. Mais tarde, alunos da Licenciatura de Língua Espanhola incorporaram-se ao projeto, para leituras em espanhol.

O trabalho iniciou-se com a inclusão de poemas de autores consagrados da língua portuguesa, como Álvares de Azevedo, Carlos Drummond de Andrade, Cecília Meireles, Manuel Bandeira, Mário Quintana e Vinícius de Moraes, entre outros.

Em seguida, com o ingresso de ledores de língua espanhola, acrescentou-se a leitura de grandes poetas da língua de Cervantes, como Alfonsina Storni, Gioconda Belli, Jorge Luís Borges, Julio Cortázar, Mario Benedetti, Pablo Neruda, entre outros.

A opção por poemas deveu-se ao fato de que os textos mais curtos serviriam de treinamento para os ledores e ao mesmo tempo seriam os mais adequados para testar 
as possibilidades de gravação e edição informatizadas. Aos poucos e com a experiência adquirida, foi possível começar a leitura de contos curtos ou trechos de romances.

O tipo de leitura realizado pelos ledores é o que se chama de leitura plana. É uma leitura com inflexão, mas sem interpretação. Respeita-se a pontuação, respeita-se a cadência do verso, mas apenas o suficiente para que a leitura seja facilmente assimilada pelo ouvinte (o leitor), sem se tornar monótona ou cansativa.

Com relação às leituras em língua estrangeira, é importante esclarecer que estas se justificam pelo fato de que entre as pessoas com deficiência visual, como qualquer outra pessoa, existem muitos interessados pelo estudo de línguas, e o material disponibilizado pode ser usado como apoio ou reforço em seus estudos. Além do mais, a internet é um veículo que não encontra fronteiras e, desta forma, se está favorecendo não só os deficientes visuais de nosso país, mas também àqueles que, em seus países de origem, talvez não tenham acesso a esse tipo de serviço.

É importante lembrar que quando falamos em inclusão, não devemos fazer separação de fronteiras. Incluir a pessoa com deficiência, é incluir a todos, universalmente, sem qualquer tipo de discriminação.

\section{CONCLUSÕES E PERSPECTIVAS}

Os resultados obtidos com este trabalho têm sido amplamente satisfatórios. Registra-se um número bastante expressivo de acessos ao site da Audioteca e freqüentemente recebemos e-mails tecendo elogios ao trabalho realizado.

Percebe-se que não apenas os deficientes visuais se beneficiam da iniciativa, mas também pessoas idosas, estudantes, professores que utilizam o material em suas aulas ou simples fãs da literatura que já se utilizavam dos serviços da Biblioteca Virtual antes do início da Audioteca.

Além disso, a Escola Luis Braille de Pelotas, voltada para a educação de crianças cegas, já recebeu duas diferentes edições em CD de áudio dos trabalhos disponibilizados pela Audioteca, para que possam alimentar sua própria audioteca.

Finalmente, no presente momento, o Curso de Licenciatura em Matemática a Distância da UFPel, que conta com sua própria biblioteca virtual, a Biblioteca Virtual de Matemática (BVM), está dando os primeiros passos no sentido de aprovar um projeto semelhante para uma audioteca que deverá cumprir seu papel inclusivo ao disponibilizar artigos e materiais didáticos da área para os cegos interessados em fazer o curso de matemática na modalidade a distância ou para professores cegos que necessitem de material para o aprofundamento de seus estudos. Sem dúvida, a possibilidade dessa tecnologia é de grande riqueza para o ensino a distância.

Com tudo isso, tem-se a segurança de que a internet e, mais especificamente, a Audioteca Virtual de Letras, cumprem um papel fundamental quando se fala de inclusão social, papel este que só tende a ampliar-se nos próximos tempos.

\section{REFERÊNCIAS BIBLIOGRÁFICAS}

ADEVA. Coordenação de Markiano Charan Filho. Criado pela Associação de deficientes visuais e amigos. 1998-2005. Apresenta textos e notícias voltadas a pessoas com deficiência visual. Disponível em: <http://www.adeva.org.br/index.htm>. Acesso em: 14 out. 2003 .

FUNDAÇÃO DORINA NOWILL PARA CEGOS. Coordenação de Alfredo Weiszflog. Criado pela Fundação Dorina Nowill para Cegos. 2001-2005. Apresenta textos e notícias voltadas a pessoas com deficiência visual. Disponível em: $<$ http://www.fundacaodorina.org.br/selecao.asp>. Acesso em: 22 nov.2003. 
GABINETE DA PRESIDÊNCIA DA REPÚBLICA. Lei nº 9610/98 - Lei brasileira de direitos autorais. Brasília, 1998.

GOES, M. H. D. A. O DOSVOX no CIOMPF: percursos, espaços e luzes. Salvador: UNEB, 2005. 61p. Monografia.

GOMES, E. P. Análise de ferramentas de auxílio aos portadores de deficiência visual na educação especial. Palmas: ULBRA, 2004. 54p.

IBC - Instituto Benjamin Constant. Coordenação de Érica Deslandes Magno Oliveira. Criado pelo Ministério da Educação. 2005. Apresenta textos e notícias voltadas a pessoas com deficiência visual. Disponível em: $<$ http://www.ibc.gov.br/Nucleus/index.php>. Acesso em 04 set.2005.

LÈVY, P. A emergência do cyberespaço e as mutações culturais. Disponível em $<$ http://www.geocities.yahoo.com.br/marceloapontes/pl_mutcult.htm> Acesso em 27 de fevereiro de 2005.

MARINHO, S. P. P. Internet na Escola. Disponível em: <http://www.educare-br.hpgig.com.br/ed390001.html> Acesso em 13 de março de 2005. In: Editorial - Abril de 1999.

MORAN, J. M. Mudar a forma de ensinar e aprender com tecnologias. Disponível em: <http://www.eca.usp.br/prof/moran/uber.htm> Acesso em 27 de janeiro de 2005. In: MORAN, J. M., MASETTO, M. e BEHRENS, M. Novas Tecnologias e Mediação Pedagógica. $7^{\mathrm{a}}$ ed. Campinas: Papirus,2003, p.11-65

RONDELLI, E. Quatro passos para a inclusão digital. Disponível em: <http://www.comunicacao.pro.br/setepontos/ano1/numero5/julho2003> Acesso em 20 de novembro de 2004.

SILVA, G. S. F. Deficiência: a inclusão do cego nas classes comuns. São José do Rio Preto: UNORP, 2003. 21p. Monografia.

SILVA FILHO, A. M. Os três pilares da inclusão digital. Disponível em: <http://www.espacoacademico.com.br/anoIII/numero24/maio2003> Acesso em 20 de novembro de 2004.

SILVEIRA, J. G. Biblioteca inclusiva? : repensando sobre barreiras de acesso aos deficientes físicos e visuais no sistema de bibliotecas da UFMG e revendo trajetória institucional na busca de soluções. Belo Horizonte: UFMG, 1999. 21p.

SPLEB. Coordenação de Carlos Alberto Gomes da Silva. Criado pela Sociedade prólivro espírita em braille. 2001-2005. Apresenta textos sobre deficiência visual e disponibiliza arquivos de áudio para cegos. Disponível em: <http://www.spleb.org.br/>. Acesso em: 18 nov.2003.

TERRA, O. G. Estudo dirigido: A educação e a informática. Disponível em: $<$ http://www.inf.ufes.br/ tavares/soft_educ.html> Acesso em 22 de novembro de 2004. 
UNESCO. Declaração dos direitos do deficiente. Rio de Janeiro, 1981.

i http://audacity.sourceforge.net/

ii http://www.ufpel.edu.br/bvl/audiotecal

iii http://www.real.com/ 